\title{
Skin Damage Among Iranian Healthcare Workers During COVID-19 Pandemic
}

\author{
Alireza Nikbakht Nasrabadi ${ }^{1}$, Touraj Harati khalilabad ${ }^{2}$, Marzieh Sobhani ${ }^{3}$, Neda \\ Sheikhzakaryaee ${ }^{4}$ and Mahboobeh Shali ${ }^{5 *}$ \\ ${ }^{1}$ Professor, school of Nursing and Midwifery, Medical surgical nursing department, Tehran University of Medical Sciences,
} Tehran, Iran

${ }^{2}$ Researcher, Department of Health Economics, School of Health Management and Health Information Sciences, Iran University of Medical Sciences, Tehran, Iran

${ }^{3}$ Instructor, Medical surgical nursing department, Islamic Azad University Dehaghan Branch, Isfahan, Iran

${ }^{4}$ Assistant Professor, Pediatric nursing department, Kurdistan University of Medical Sciences, Sanandaj, Iran

${ }^{5}$ Critical care nursing and management department, school of Nursing and Midwifery, Tehran University of Medical Sciences, Tehran, Iran

*Corresponding author: Mahboobeh Shali, School of Nursing and Midwifery, Doctor Mirkhani St, Tohid Sq, Tehran, Iran

\section{ARTICLE INFO}

Received: 慧 December 16, 2020

Published: 幽 December 23, 2020

Citation: Alireza Nikbakht Nasrabadi, Touraj Harati khalilabad, Marzieh Sobhani, Neda Sheikhzakaryaee, Mahboobeh Shali. Skin Damage Among Iranian Healthcare Workers During COVID-19 Pandemic. Biomed J Sci \& Tech Res 32(5)-2020. BJSTR. MS.ID.005305.

\section{ABSTRACT}

Due to the growing trend of COVID-19 incidence in societies, HCWs are faced with an additional workload and stress. Skin damage caused by enhanced infection-prevention measures among health care workers. This study aims to estimate the prevalence and clinical features of this skin damage among Iranian Healthcare workers. six hundred HCWs were surveyed between June to August 2020. Questionnaires were used to assess skin damage due to PPE. Hand dryness accounted for the most skin damages. It is necessary to pay attention to the needs and health of the HCWs, as the main health care providers. Providing standard equipment, proper working conditions, and designing appropriate guidelines for the use of PPE are essential.

Keywords: Healthcare Workers; Skin Damage; COVID-19 Pandemic; Iran

\section{Introduction}

COVID-19 is an infectious disease caused by a newly discovered coronavirus [1]. In Iran, the first case of COVID-19 was reported on 19th February in Qom city, and since it had spread rapidly in neighboring provinces [2]. Due to the growing trend of COVID-19 incidence in societies, HCWs are faced with an additional workload and stress. Skin damage caused by enhanced infection-prevention measures among health care workers. Considering the frequent hand hygiene and long-time wearing of Personal Protective Equipment (PPE) among healthcare workers during the epidemic period of COVID-19, we aimed to estimate the prevalence and clinical features of this skin damage among them.

\section{Methods}

This cross-sectional study was carried out from June to August 2020 in Tehran. six hundred HCWs (physician, nurse, physiotherapist, and midwife) working in hospitals affiliated to Tehran University of Medical Sciences were selected to take part in this study. Only HCWs who directly provided care to COVID-19 patients and were obliged to use PPE at their shift were included in this study. A questionnaire that had two sections was used to collect the data. The first part of questionnaire included questions about demographic characteristics including age, gender, occupation, 
work experience, and background history. Also, we used Jiajia Lan et al (2020) skin damages questionnaire to assess damages caused by the use of PPE [3]. This questionnaire consisted of three sections: symptoms, type, and site of skin damage. These questions required a simple - 'Yes' and 'No'- answers. Tehran University of Medical Sciences' Ethics Committee approved this study. The participants were informed of the objectives and method of study, and an informed written consent was obtained from all participants.

\section{Results}

The demographic characteristics of the participants are presented in Table 1. The most prevalent skin damages were seen in hands, nose bridge, forehead, and cheeks with symptoms of stiffness, dry skin, erythema, and redness, respectively (Table 2).

Table 1: Demographic characteristics of the HCWs.

\begin{tabular}{|c|c|c|c|}
\hline \multirow{4}{*}{ Age } & \multirow{2}{*}{$20-30$} & $\mathrm{n}$ & $\%$ \\
\hline & & 278 & 46.3 \\
\hline & $31-40$ & 256 & 42.6 \\
\hline & $41-50$ & 66 & 11.1 \\
\hline \multirow{2}{*}{ Sex } & Male & 262 & 43.6 \\
\hline & Female & 338 & 56.4 \\
\hline \multirow{4}{*}{ Profession } & Physician & 134 & 22.3 \\
\hline & Nurse & 338 & 56.3 \\
\hline & Physiotherapist & 64 & 10.7 \\
\hline & Midwife & 64 & 10.7 \\
\hline \multirow{3}{*}{ Work experience } & $1-10$ & 268 & 44.6 \\
\hline & $11-20$ & 196 & 32.7 \\
\hline & $21-30$ & 136 & 22.7 \\
\hline \multirow{2}{*}{ Underlying comorbidities } & Yes & 196 & 32.6 \\
\hline & No & 404 & 67.4 \\
\hline
\end{tabular}

Table 2: Skin damage among healthcare workers.

\begin{tabular}{|c|c|c|c|}
\hline \multirow{4}{*}{ Symptoms } & Dryness/tightness & $\mathrm{n}$ & $\%$ \\
\cline { 2 - 4 } & Tenderness & 297 & 99 \\
\cline { 2 - 4 } & Itching & 201 & 67 \\
\cline { 2 - 4 } & Burning/pain & 112 & 37 \\
\hline \multirow{4}{*}{ Side effects type } & Desquamation & 216 & 72 \\
\cline { 2 - 4 } & Erythema & 225 & 75 \\
\cline { 2 - 4 } & Maceration & 119 & 39 \\
\cline { 2 - 4 } & Fissure & 112 & 37 \\
\cline { 2 - 4 } & Papule & 27 & 09 \\
\cline { 2 - 4 } & Erosion & 93 & 31 \\
\cline { 2 - 4 } & Ulcer & 29 & 09 \\
\cline { 2 - 4 } & Vesicle & 56 & 18 \\
\cline { 2 - 4 } & Wheal & 13 & 04 \\
\hline
\end{tabular}

\begin{tabular}{|c|c|c|c|}
\hline \multirow{3}{*}{ Site } & Nasal bridge & 287 & 95 \\
\cline { 2 - 4 } & Cheek & 172 & 57 \\
\hline \multirow{3}{*}{} & Hands & 290 & 96 \\
\cline { 2 - 4 } & Forehead & 183 & 61 \\
\hline
\end{tabular}

\section{Discussion}

In the present study, the most common skin lesions were on the hands and bridge of the nose. A study conducted by Lan et al in China showed that skin damages were mostly seen on nose bridge and cheeks [3]. In another study, huh reported that hand eczema was a common complication among health workers in China [4]. Also, Desai et al stated that tighter and more secure N95 masks can cause significant skin damage due to pressure on bridge of the nose and across the zygoma [5]. Wear facial PPE correctly and make sure size is correct. Ensuring the proper use of PPE and their proper size can greatly reduce the damage induced. In this study, dry skin and xerosis were common side effects reported by the healthcare worker, which is consistent with the findings of Lan et al study [3]. Covering the site with a bandage or protective material under the adhesive or skin surface can prevent this problem [4]. Minimizing the side effect of PPE use will help to improve adherence to PPE.

\section{Conclusion}

To reduce the burden of COVID-19 and accelerate the process of patient treatment, it is necessary to pay attention to the needs and health of the HCWs, as the main health care providers. Providing standard equipment, proper working conditions, and designing appropriate guidelines for the use of PPE are essential.

\section{References}

1. Li Q, Guan X, Wu P (2020) Early transmission dynamics in Wuhan, China, of novel coronavirus-infected pneumonia. N Engl J Med 382: 1199-207.

2. Online news. Ministry of Health and Medical Education website. http:// dme. behdasht.gov.ir/index.aspx?siteid=1\&pageid=3127. Published 2020.

3. Lan J, Song Z, Miao X, Li H, Li Y, et al (2020) Skin damage among health care workers managing coronavirus disease-2019. J AM ACAD DERMATOL 82(5): 1215-1216.

4. Huh S (2020) How to train health personnel to protect themselves from SARS-CoV-2 (novel coronavirus) infection when caring for a patient or suspected case. J Educ Eval Health Prof 17(10): 1-6.

5. Desai S, Kovarik C, Brod B, James W, Fitzgerald M, et al (2020) COVID-19 and personal protective equipment: Treatment and prevention of skin conditions related to the occupational use of personal protective equipment. J AM ACAD DERMATOL 83(2): 675-677. 
ISSN: 2574-1241

DOI: 10.26717/BJSTR.2020.32.005305

Mahboobeh Shali. Biomed J Sci \& Tech Res

(c) (P) This work is licensed under Creative

Submission Link: https://biomedres.us/submit-manuscript.php

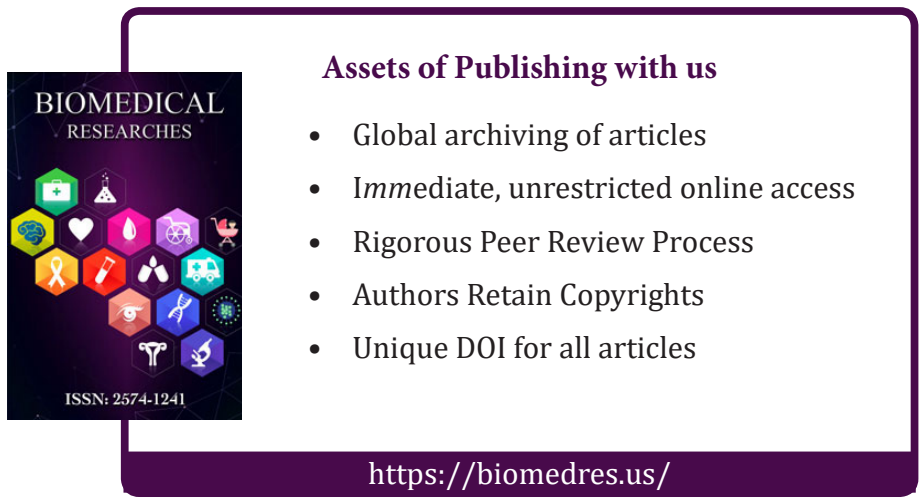

